Journal Wetenskap Health

\title{
Family Support with Elderly Independence in Fulfilling Activities Physical and Mental Health
}

\author{
Fathy Ramadhon Sobhi ${ }^{1}$, Mervat Sedki ${ }^{1}$ \\ ${ }^{1}$ Faculty of Public Health, Alexandria University, Egypt
}

\begin{abstract}
Physical, mental, and emotional changes in the elderly need family care, since family assistance alleviates aging difficulties. They need the assistance of individuals close to them to be able to enjoy life in old age and be happy or feel pleased. Older reliance is created by the fact that many elderly individuals are suffering from physical, cognitive, and psychological decline, which means that the elderly are going through changes that are unfavorable. As a consequence, physical mobility issues will impede the elderly's ability to carry out everyday tasks independently. Family serves as a secure and serene haven for relaxation and healing, as well as a tool for mastering emotions such as empathy, care, and concern for the elderly.
\end{abstract}

Keywords: Family Support, Elderly Health Activities, Mental Health

\section{Introduction}

Changes in brain structure in the aged produce a deterioration in quality of life, which has consequences for everyday activities independently. Elderly independence in ADL (activities of daily living) is described as a person's ability to carry out activities and functions of daily life that are frequently and universally performed by humans. It is critical for an individual to be self-sufficient in addressing fundamental human requirements. Although younger family members find it difficult to accept their parents' full and sluggish everyday activities. Because family assistance aids senior difficulties, changes in the old, both physically, cognitively, and emotionally, need family assistance. They need the assistance of individuals close to them to be able to enjoy life in old age and be happy or feel pleased. Older reliance is created by the fact that many elderly individuals are suffering from physical, cognitive, and psychological decline, which means that the elderly are going through changes that are unfavorable. As a consequence, physical mobility issues will impede the elderly's ability to carry out everyday tasks independently. Tasks of daily living (ADL) are the freedom to act without relying on others for personal care and everyday activities. The elderly who are more functionally independent have a greater chance of surviving illness assaults. The elderly who exhibit signs of dependency, on the other hand, will be prone to illness assaults. Rheumatoid arthritis, hypertension, bronchitis, diabetes mellitus, injury, stroke, $\mathrm{TB}$, and bone fractures are all common diseases among the elderly who are dependent.

\section{Elderly Health Condition}

Those who are physically and mentally in excellent enough health enjoy the maximum amount of freedom. Those in excellent health have the greatest proportion. They

Article Info:

Received: April 12, 2021

Revised: May 15, 2021

Accepted: May 26, 2021 
may undertake any activity in their everyday lives, including self-care, employment, and enjoyment, if they are in excellent health. This is in keeping with the belief that the elderly's independence may be measured by their health and ability to carry out everyday tasks (ADL). Standard ADL and instrumental ADL are the two types of ADL. Self-care skills such as eating, dressing, defecating/urinating, and bathing are included in the standard ADL.

Meanwhile, instrumental ADL covers a wide range of tasks such as cooking, washing, talking on the phone, and handling money. Meanwhile, the elderly who are in good health are less likely to be self-sufficient. This is because their physical and mental health conditions are occasionally unwell or have issues, preventing them from doing all of their everyday duties alone. They need assistance from others in various tasks, such as heavy lifting or making judgments. Elderly persons in excellent health may participate in any activity, but those in average health choose occupations that involve less physical exertion. They need assistance from others to carry out certain difficult physical and psychological duties. As a person's health state deteriorates, they become more interested in things that demand less energy and physical exercise.

\section{Changes in the Elderly Both Physically, Mentally, and Emotionally}

Family support is important for the elderly because it helps them deal with their challenges. They need the assistance of individuals close to them to be able to enjoy life in old age and be happy or feel pleased. Old reliance is caused by the aged's state, which includes several physical, cognitive, and psychological decreases, implying that the elderly experience development in the form of negative alterations.

As a consequence, physical mobility issues will impede the elderly's ability to carry out everyday tasks independently. Tasks of daily living (ADL) are the freedom to act without relying on others for personal care or everyday activities. The elderly who are more functionally independent have a greater chance of surviving illness assaults. The elderly who exhibit signs of dependency, on the other hand, will be prone to illness assaults. Rheumatoid arthritis, hypertension, bronchitis, diabetes mellitus, injury, stroke, TB, and bone fractures are all common diseases among the elderly who are dependent.

The advantages of family engagement will enhance members' health and well-being, particularly the old (Jetten et al., 2014; Roy et al., 2014; Leedahl et al., 2011; Horowitz \& Chang, 2004). The elderly's capacity to complete daily tasks will improve if they get appropriate family assistance and are encouraged to be self-sufficient in daily activities, hence improving their health state (However, many elderly people who live with their families report a loss of independence. This is due to the fact that many senior families are preoccupied with their different occupations, and the rising economic necessities force all family members to work outside the house, forcing families who care for the elderly to pay less attention to or give optimum assistance to the elderly. Elderly who are not self-sufficient and do not have family help will rely on satisfying daily tasks, which will affect their health and make them more prone to illness. Family assistance is one method that may be used to promote the independence of the elderly in everyday activities. Family members may be able to help (children, wife, husband and relatives).

This assistance may take the form of tips reminding the elderly not to work excessively (if they are still working), providing opportunity for the elderly to engage in activities that become hobbies, providing opportunity for the elderly to worship properly, and providing appropriate rest time for the elderly to avoid being worried and nervous. As a 
result, it is intended that the elderly would continue to have a high quality of life, be able to carry out daily tasks independently, and preserve their health.

\section{Social Condition}

Enjoying social activities with family and friends is a vital prerequisite for older people to be happy. The social interaction between the elderly and their adult children is influenced by the closeness of their connection and the child's obligation to their parents, both of which contribute to the elderly's independence. Children who have grown up, whether married or not, and who live in the same home, do not live in the same home but are close to their place of residence, or who live far away (living outside the city) are still responsible for the elderly's requirements, such as clothes, food, health, and social requirements. Children owe it to their parents to support them as a token of appreciation for their parents' efforts in raising them. Old children are likewise fair and kind in caring for and aiding their elderly parents (in line with Pancasila's second principle). The attitudes of mature children toward aging parents, as well as regular interaction with them, may help older individuals make excellent social and personal changes.

\section{Types of Family Support}

Family serves as a secure and relaxing environment for relaxation and healing, as well as assisting in the mastery of emotions, such as demonstrations of empathy, care, and concern for the elderly. The family serves as a source and validator of member identity, as well as a feedback guide, directing and mediating settlement. In the elderly, it occurs via positive expressions of regard (appreciation), encouragement for growth, or agreement with particular views or sentiments, as well as favorable comparisons. The family may provide real and actual aid in the form of money, equipment, time, environmental change, and job aid when you're stressed.

The family serves as a collector and disseminator of global knowledge, which includes providing guidance, instructions, tools, and feedback (Leavitt \& Shneiderman, 2006). Encouragement, counseling, and supervision concerning daily meals and medicines are examples of the family's support. Family support is an unique sensation that is noticed, valued, and respected, as well as being a member of the community. The major family role is to teach everything in order to prepare family members to interact with others. The socialization function is the process of preparing children for social life before they leave the house to interact with other people. Reproductive function is a function that ensures the continuance of generations and families (Wooten, 2009). The family's economic purpose is to satisfy the requirements of the family financially, as well as to develop individual capacities in growing revenue to fulfill those requirements. The health care and maintenance function is responsible for maintaining the health of family members in order to sustain high productivity.

\section{Function of Independence in the Elderly}

The elderly have the capacity to not rely on others to carry out their activities; everything is done alone, with their own judgments, to fulfill their demands. Furthermore, the elderly's quality of life reflects their independence. The capacity to undertake everyday tasks may be used to measure the elderly's quality of life. Standard ADL and instrumental ADL are the two types of activities of daily living (ADL). Self-care skills such as eating, dressing, defecating/urinating, and bathing are all part of the standard ADL. Meanwhile, instrumental 
ADL encompasses a wide range of tasks such as cooking, washing, talking on the phone, and managing money.

\section{The Characteristics of the Form of Family Support}

The features of each kind of family social support are as follows: Informative, i.e., information assistance offered so that it may be utilized by someone in addressing the issues at hand, such as offering counsel, guidance, ideas, or other information required, and this information is then passed on to others who may be facing the same or similar issues. Emotional support, everyone requires affection from others; this support may come in the form of sympathetic and compassionate support, love, trust, and gratitude. As a result, a person experiencing difficulties may feel as though he is not alone, as others pay attention, want to hear all of his complaints, sympathize, and empathize with his troubles. Instrumental support seeks to make it simpler for someone to carry out their tasks linked to the issues they are experiencing, or to directly support them in overcoming their difficulties, such as by providing full and suitable equipment for sufferers, supplying essential medications, and so on. Assessment Assistance is a sort of appreciation offered by one person to another depending on the patient's real state. This evaluation may be either good or negative, and it may mean a lot to someone. A very beneficial evaluation is a good evaluation when it comes to family social assistance.

Family social support is a continuous process that takes place throughout one's life. At various periods of life, the form and degree of social support varies (Uchino, 2008; Brown et al., 2003; Caldwell, 2004). Family social support, on the other hand, allows the family to operate with varied intelligences and senses at different phases of life. This benefits the family's health and adaptability.

The elderly's capacity to complete daily tasks is enhanced if adequate family assistance is offered, and the old are encouraged to be self-sufficient in daily activities, hence improving their health state. However, many elderly people see a reduction in independence among the elderly who live with their families. This is due to the fact that many senior families are preoccupied with their individual employment, in addition to the fact that rising economic necessities force all family members to work outside the house, forcing families with elderly people to pay less attention to or provide optimum assistance for the elderly. Elderly who are not self-sufficient and do not get family help rely on the completion of daily tasks, which has an influence on their health and makes them more prone to illness. Family assistance is one method that may be used to promote the independence of the elderly in everyday activities. Family members may be able to help (children, wife, husband and relatives). This assistance may take the form of tips reminding the elderly not to work excessively (if they are still working), providing opportunity for the elderly to engage in activities that become hobbies, providing opportunity for the elderly to worship properly, and providing appropriate rest time for the elderly to avoid being worried and nervous. As a result, it is intended that the elderly would continue to have a high quality of life, be able to carry out daily tasks independently, and preserve their health.

Changes in brain structure in the aged produce a deterioration in quality of life, which has consequences for everyday activities independently. a person's autonomy in carrying out tasks and duties of everyday life that are frequently and universally carried out by people. It is critical for an individual to be self-sufficient in addressing fundamental human requirements. Although younger family members find it difficult to accept their parents' full and sluggish everyday activities. 


\section{Conclusion}

The elderly has the capacity to not rely on others to carry out their activities; everything is done alone, with their own judgments, to fulfill their demands. The elderly's capacity to complete daily tasks is enhanced if adequate family assistance is offered, and the old are encouraged to be self-sufficient in daily activities, hence improving their health state. Family members may be able to help (children, wife, husband and relatives). This assistance may take the form of tips reminding the elderly not to work excessively (if they are still working), providing opportunity for the elderly to engage in activities that become hobbies, providing opportunity for the elderly to worship correctly, and providing appropriate rest time for the elderly to avoid stress and concern.

\section{References}

Brown, S. L., Nesse, R. M., Vinokur, A. D., \& Smith, D. M. (2003). Providing social support may be more beneficial than receiving it: Results from a prospective study of mortality. Psychological science, 14(4), 320-327.

Caldwell, M. L. (2004). Not by bread alone: social support in the new Russia. Univ of California Press.

Horowitz, B. P., \& Chang, P. F. J. (2004). Promoting well-being and engagement in life through occupational therapy lifestyle redesign: A pilot study within adult day programs. Topics in Geriatric Rehabilitation, 20(1), 46-58.

Jetten, J., Haslam, C., Haslam, S. A., Dingle, G., \& Jones, J. M. (2014). How groups affect our health and well-being: The path from theory to policy. Social issues and policy review, 8(1), 103-130.

Leavitt, M. O., \& Shneiderman, B. (2006). Based web design \& usability guidelines. Health and Human Services Department.

Leedahl, S. N., Koenig, T. L., \& Ekerdt, D. J. (2011). Perceived benefits of VFW post participation for older adults. Journal of gerontological social work, 54(7), 712-730.

Roy, M. J., Donaldson, C., Baker, R., \& Kerr, S. (2014). The potential of social enterprise to enhance health and well-being: A model and systematic review. Social Science \& Medicine, 123, 182-193.

Uchino, B. N. (2008). Social support and physical health. Yale university press.

Wooten, E. (2009). "The Family Life that Does not Die with Death": Continuity, Reproduction, and Inheritance in the Novels of EM Forster. 